\title{
BMJ Open Improving developmental and educational support for children born preterm: evaluation of an e-learning resource for education professionals
}

\author{
Samantha Johnson, ${ }^{1}$ Deborah Bamber, ${ }^{1}$ Vasiliki Bountziouka, ${ }^{1}$ Sarah Clayton, ${ }^{1}$ \\ Lucy Cragg, ${ }^{2}$ Camilla Gilmore, ${ }^{3}$ Rose Griffiths, ${ }^{4}$ Neil Marlow, ${ }^{5}$ Victoria Simms, ${ }^{6}$ \\ Heather $\mathrm{J}$ Wharrad $^{\bullet 7}$
}

To cite: Johnson S, Bamber D,

Bountziouka V, et al. Improving developmental and educational support for children born preterm: evaluation of an e-learning resource for education professionals. BMJ Open 2019;9:e029720. doi:10.1136/ bmjopen-2019-029720

- Prepublication history and additional material for this paper are available online. To view these files, please visit the journal online (http://dx.doi. org/10.1136/bmjopen-2019029720).

Received 7 February 2019 Revised 2 April 2019 Accepted 10 May 2019
Check for updates

(C) Author(s) (or their employer(s)) 2019. Re-use permitted under CC BY-NC. No commercial re-use. See rights and permissions. Published by BMJ.

For numbered affiliations see end of article.

Correspondence to Dr Samantha Johnson; sjj19@le.ac.uk

\section{ABSTRACT}

Objectives Children born preterm are at higher risk for special educational needs and poor academic attainment compared with term-born peers, yet education professionals receive limited training and have poor knowledge of preterm birth. We have developed an interactive e-learning resource and evaluated its efficacy in improving teachers' knowledge of preterm birth and their confidence in supporting the learning of children born preterm.

Setting Eight primary, infant or junior schools in England. Participants 61 teachers of children aged 4-11 years, of which 55 (90\%) were female.

Intervention Interactive e-learning resource designed to improve education professionals' knowledge of longterm outcomes following preterm birth and strategies that can be used to support children's learning (www. pretermbirth.info). In a repeated measures design, participants were given up to 30 days access to the e-learning resource, before and after which they completed the Preterm Birth Knowledge Scale (PB-KS; scores 0-33; higher scores indicate greater knowledge) to assess knowledge of outcomes of prematurity. Four Likert scale items were used to assess confidence in supporting children's learning and 10 items were used to evaluate the utility of the resource. PB-KS scores and responses on confidence item were compared preresource and post-resource use.

Results PB-KS scores significantly increased after accessing the e-learning resource (median $(95 \% \mathrm{Cl})$ : pre-resource 13 (11 to 14); post-resource 29 (28 to 30)), equating to a 2.6 SD increase in PB-KS scores. Teachers' confidence in supporting children born preterm was also significantly improved after using the resource. The utility of the resource was evaluated positively by participants with $97 \%$ reporting that they would recommend its use to others.

Conclusions The e-learning resource substantially improved teachers' knowledge of preterm birth and their confidence in supporting preterm children in the classroom. Use of this resource may represent a key advance in improving educational outcomes for children born preterm.
Strengths and limitations of this study

- We have developed a novel, interactive e-learning resource about preterm birth and its impact on children's development and learning for use by education professionals.

- This e-learning resource significantly improves education professionals' knowledge of the consequences of preterm birth and their confidence in supporting the learning of children born preterm.

- The utility of the e-learning resource was evaluated extremely positively by education professionals.

- The e-learning resource is available for use non-commercially at www.pretermbirth.info.

- Further research is needed to determine whether use of the e-learning resource contributes to improved educational outcomes for children born preterm.

\section{INTRODUCTION}

Preterm birth places children at increased risk for a range of developmental problems and disorders later in life. The most common adverse outcomes are intellectual impairments, deficits in working memory, visuospatial skills, processing speed and executive functions, and attention, social and emotional problems. ${ }^{1-3}$ As these difficulties can have a profound effect on a child's performance at school, it is unsurprising that children born preterm are at increased risk for special educational needs (SEN) and poorer academic attainment compared with their term born peers. ${ }^{4-6}$ This disadvantage persists throughout the lifespan with fewer preterm-born adults having completed high school and undertaken higher education. ${ }^{7-9}$ The well documented dose-response effect of gestation means that the more preterm a baby is born the greater the risk of difficulties later in life. However, poor educational 
outcomes are not confined just to those born very preterm ( $<32$ weeks' gestation), as evidenced by an increased risk for SEN and lower academic attainment among children born just a few weeks early. ${ }^{4510}$

Knowledge and preparation about chronic health conditions is considered crucial for appropriate educational management, ${ }^{11}{ }^{12}$ and teachers need to feel confident in how to support children with SEN to be able to meet their needs in the classroom. ${ }^{13}$ However, education professionals receive very little training about the impact of preterm birth on children's development and learning and have poor knowledge of how to support pretermborn children in the classroom. ${ }^{14}$ In a recent national survey, only $16 \%$ of teachers had received any training about preterm birth and over $90 \%$ expressed the need for training. ${ }^{14}$ As teachers have primary responsibility for supporting the learning and development of pretermborn children in the long term, this represents a significant public health concern.

In order to address this unmet need, we have developed an e-learning resource for education professionals to provide information about preterm birth and practical strategies that can be used to support children who have the cognitive, learning and social-emotional difficulties most frequently associated with preterm birth. The aim of the present study was to evaluate the efficacy of this resource in improving teachers' knowledge of the consequences of preterm birth and their confidence in supporting the learning of children born preterm.

\section{METHODS}

\section{Participants}

The head teachers of eight primary, infant or junior schools in Nottinghamshire and Derbyshire in England agreed to allow their staff to be invited to take part in the study. Head teachers handed out study information packs and written informed consent was obtained for all staff who participated in the study.

\section{Procedure}

After providing consent, participants were requested to setup a personal account on an open-source learning platform in order to complete study questionnaires and access the e-learning resource. Participants were then asked to $\log$ in to their account to complete a pre-resource use questionnaire, after which they were provided with access to the e-learning resource. Once participants indicated that they had finished using the resource, or following a reminder sent after 30 days, participants were able to access and complete the post-resource use questionnaire, also via the online platform. For six participants who experienced technical difficulties using the online platform, the same data were collected using JISC online surveys (www.jisc.ac.uk) and access to the resource was provided via weblinks in an email. After completing the post-resource questionnaire, teachers received certificates to confirm their participation in the study.

\section{Preterm birth e-learning resource}

An interactive e-learning resource was developed which comprised five discrete reusable learning objects (RLOs). RLOs comprise a mixture of multimedia elements including audio, video, animation, text, images, case studies and quizzes designed to engage the user in active learning and allowing individuals to set their own pace of learning. ${ }^{15}$ RLOs have received positive evaluation by users worldwide ${ }^{16}$ and have been shown to be effective in increasing learning, self-confidence and skills in a range of health and education disciplines. ${ }^{17-19}$ The RLOs comprise evidence-based information about outcomes of preterm birth and strategies education professionals can use to support learning for children with the cognitive, mathematics and social-emotional difficulties most commonly associated with preterm birth (online supplementary appendix table S1). The focus of each of the RLOs is as follows:

RLO 1: What is preterm birth?

RLO 2: Educational outcomes following preterm birth.

RLO 3: Cognitive and motor development following preterm birth.

RLO 4: Behavioural, social and emotional outcomes following preterm birth.

RLO 5: How can education professionals support children born preterm?

The resource represents $\sim 1$ hour of learning activity and is freely available for use at www.pretermbirth.info.

\section{Patient and public involvement}

The e-learning resource was developed using a participatory methodology in which 26 key stakeholders codesigned the RLOs. Stakeholders comprised teachers, teaching assistants, educational psychologists, parents of children or young adults born preterm, and young adults themselves born preterm. These stakeholders attended a workshop during which they developed storyboards to guide the content and design of the resource. These were subsequently distilled into written content specifications that were reviewed by experts in the field for accuracy and content and then used to produce the resource. Prototype versions of the RLOs were reviewed by two teachers who provided feedback that was incorporated into the final version of the resource. Study results have been disseminated to participants via a newsletter and stakeholders have received email updates on the development of the resource.

\section{Measures}

To assess knowledge of the outcomes of prematurity pre-resource and post-resource use, participants completed the Preterm Birth Knowledge Scale (PB-KS), ${ }^{20}$ a validated scale comprising 33 statements for which participants indicate whether the statement is 'true', 'false' or 'don't know'. Each statement is scored for accuracy (correct $=1$; incorrect/don't know=0) and a total PB-KS score (range $0-33$ ) is computed; higher scores indicate greater knowledge. The PB-KS has excellent internal consistency in 
samples of health professionals (Cronbach's $\alpha=0.82)^{20}$ and teaching staff (Cronbach's $\alpha=0.81$ ), ${ }^{14}$ and construct validity in discriminating the knowledge levels of neonatal clinicians and teachers. ${ }^{1420}$

To assess confidence in supporting the learning of preterm-born children pre-resource and post-resource use, participants indicated the extent to which they agreed with four statements using a 5-point Likert scale (strongly agree; agree; neither agree nor disagree; disagree; strongly disagree; online supplementary appendix table S2). After using the resource, participants were also asked to rate how strongly they agreed with 10 statements about the utility of the resource using the same 5-point scale (online supplementary appendix table S3).

In order to describe the sample, basic demographic information relating to gender, professional roles and the number of years spent teaching were collected in the pre-resource questionnaire.

\section{Statistical analysis}

Data were analysed using SPSS V.24.0. Total PB-KS scores were computed and change in median PB-KS score pre-resource versus post-resource use was compared using the Wilcoxon signed-rank test as data were not normally distributed. For items assessing confidence, responses were dichotomised (strongly agree/agree vs. neither agree nor disagree/disagree/strongly disagree) and the proportion of participants agreeing with each statement was compared pre-resource versus post-resource use using the McNemar test. A post-hoc power analysis confirmed that the final sample $(n=61)$ was sufficient to detect a difference of at least 3 units $(\mathrm{SD}=7)$ in the $\mathrm{PB}-\mathrm{KS}$ score pre-resource versus post-resource use with a power of $90 \%$ at the 0.05 significance level.

\section{RESULTS}

\section{Sample characteristics}

Of 120 teachers who consented to take part, 71 completed the pre-resource questionnaire. Of these, 61 accessed the e-learning resource and completed the post-resource questionnaire. The final sample thus comprised 61 participants. Basic demographic characteristics are shown in table 1. Fifty-five (90\%) participants were female and half the sample (52\%) were Key Stage 2 teachers of children aged 7-11 years; the remaining half split equally between Foundation Stage and Key Stage 1 teachers. Almost half were class teachers $(48 \%)$ and there was representation from all key professional roles including teaching assistants, head teachers and SEN coordinators. The majority $(85 \%)$ reported that they had previously received information about preterm birth.

\section{Knowledge of preterm birth}

The median total PB-KS score significantly increased after participants used the e-learning resource: pre-resource median 13 (95\% CI 11 to 14; range 0-25); post-resource median 29 (95\% CI 28 to 30; range 18-33); $\mathrm{p}<0.0001$.
Table 1 Characteristics of study participants $(n=61)$

\begin{tabular}{|c|c|}
\hline Characteristic & n (\%) \\
\hline \multicolumn{2}{|l|}{ Gender, n (\%) } \\
\hline Male & $6(10)$ \\
\hline Female & $55(90)$ \\
\hline \multicolumn{2}{|l|}{ Professional roles, $\mathrm{n}(\%)^{\star}$} \\
\hline Classroom teacher & $29(48)$ \\
\hline $\begin{array}{l}\text { Teaching assistant or higher level teaching } \\
\text { assistant }\end{array}$ & $24(39)$ \\
\hline Special educational needs coordinator & $4(6.6)$ \\
\hline Head teacher & $4(6.6)$ \\
\hline Deputy or assistant head teacher & $9(15)$ \\
\hline Other & $6(9.8)$ \\
\hline \multicolumn{2}{|l|}{ No of years teaching, $n(\%)$} \\
\hline $1-5$ & $11(18)$ \\
\hline $6-10$ & $12(20)$ \\
\hline $11-15$ & $7(12)$ \\
\hline $16-20$ & $13(21)$ \\
\hline $21-25$ & $10(16)$ \\
\hline $26-30$ & $5(8.2)$ \\
\hline$\geq 31$ & $3(4.9)$ \\
\hline \multicolumn{2}{|l|}{ Age of children taught in main role, $\mathrm{n}(\%)^{\star *}$} \\
\hline Foundation stage (reception year; ages 4-5) & $13(24)$ \\
\hline Key stage 1 (years 1 and 2; ages 5-7) & $13(24)$ \\
\hline Key stage 2 (years 3 to 6; ages 7-11) & $28(52)$ \\
\hline \multicolumn{2}{|c|}{$\begin{array}{l}\text { Previously received information during training about preterm } \\
\text { birth, } \mathrm{n}(\%)\end{array}$} \\
\hline Yes & $52(85)$ \\
\hline No & $5(8.2)$ \\
\hline Not sure & $4(6.6)$ \\
\hline
\end{tabular}

Experience of children born preterm in close family or friends, $n$ (\%)

$\begin{array}{lc}\text { Yes } & 35(57) \\ \text { No } & 23(38) \\ \text { Not sure } & 3(4.9) \\ \text { Experience of working with children born preterm, } \mathrm{n}(\%) \\ \text { Yes } & 11(18) \\ \text { No } & 29(48) \\ \text { Not sure } & 21(34)\end{array}$

*More than one professional role may be selected.

${ }^{* *} \mathrm{n}=7$ were excluded as they were not classroom teachers.

The mean (SD) PB-KS score pre-resource use was 13 (6.2) and post-resource use was 28 (3.5), equating to a 2.6 SD increase in scores. The accuracy of participants' responses improved after accessing the resource on all 33 PB-KS items, with percent difference in accuracy ranging from $3 \%$ to $93 \%$ (table 2). The greatest improvement in knowledge related to the risk for mathematics difficulties $(93 \%)$, poor social skills $(79 \%)$, inattention $(74 \%)$ 
Table 2 Accuracy of responses on individual Preterm Birth Knowledge Scale (PB-KS) items before and after accessing the e-learning resource

\section{PB-KS items}

Preresource Postresource \% diff postresource n (\%) correct

1. The more premature a baby is born, the more likely he or she will have problems later in life

$41(67)$

2. Almost all children born very preterm will have cerebral palsy

3. Even babies who are born just 1 or 2 weeks early may have special educational needs
4. Children born very preterm will catch-up with their peers by the end of 21 (34) primary school

$\begin{array}{lll}51(84) & 60(98) & 15(5 \text { to } 25) \\ 25(41) & 50(82) & 41(29 \text { to } 57)\end{array}$

5. $20 \%$ of all children born very preterm will be blind or deaf

6. Children born very preterm are at higher risk for attention deficit/ hyperactivity disorder) than children who were born at term

\section{Even children born very preterm without obvious disabilities may have $35(57)$} learning difficulties and poor performance at school

$\begin{array}{lll}14(23) & 49(80) & 57(47 \text { to } 72) \\ 10(16) & 51(84) & 67(58 \text { to } 80)\end{array}$

8. Children born very preterm are likely to be inattentive and withdrawn 9 (15)

9. Children born very preterm will catch-up with their peers by the end of $15(25)$ secondary school

10. Only a small proportion of children born very preterm will have severe 25 (41) disabilities later in life

\section{Children born very preterm who have learning difficulties may not be 12 (20)} noticed as they tend not to disrupt the classroom

12. Children born very preterm have similar levels of academic attainment 28 (46) to their peers born at term

\begin{tabular}{|c|c|c|c|}
\hline $\begin{array}{l}\text { 13. } 20 \% \text { of children born very preterm are likely to have autism spectrum } \\
\text { disorders }\end{array}$ & $9(15)$ & $41(67)$ & 52 (44 to 67$)$ \\
\hline $\begin{array}{l}\text { 14. Children born very preterm are likely to be hyperactive and disruptive } \\
\text { in the classroom }\end{array}$ & $26(43)$ & $51(84)$ & 41 (29 to 56 ) \\
\hline
\end{tabular}
in the classroom

\begin{tabular}{|c|c|c|c|}
\hline $\begin{array}{l}\text { 15. Every child born very preterm will have some degree of learning } \\
\text { difficulties }\end{array}$ & $31(51)$ & $41(67)$ & $16(4$ to 34$)$ \\
\hline $\begin{array}{l}\text { 16. Almost all children born very preterm are likely to have breathing } \\
\text { difficulties and need an inhaler throughout childhood }\end{array}$ & $21(34)$ & $44(72)$ & 38 (26 to 54$)$ \\
\hline $\begin{array}{l}\text { 17. Children born very preterm have poorer performance in all national } \\
\text { curriculum subjects compared with children born at term }\end{array}$ & $17(28)$ & $45(74)$ & 46 (35 to 62$)$ \\
\hline 18. Children born very preterm tend to have poorer social skills than & $9(15)$ & $57(93)$ & $79(70$ to 90$)$ \\
\hline
\end{tabular}
children born at term

\begin{tabular}{|c|c|c|c|}
\hline $\begin{array}{l}\text { 19. Children born very preterm have similar IQ scores to their peers born } \\
\text { at term }\end{array}$ & $19(31)$ & $54(89)$ & 66 (54 to 77$)$ \\
\hline 20. Almost all children born very preterm are likely to need one-to-one & $39(64)$ & $51(84)$ & 20 (8 to 35$)$ \\
\hline
\end{tabular}
support in the classroom

\begin{tabular}{|c|c|c|c|}
\hline $\begin{array}{l}\text { 21. Children born very preterm are more likely to have behavioural and } \\
\text { emotional problems than children who were born at term }\end{array}$ & $16(26)$ & $43(70)$ & 44 (33 to 60$)$ \\
\hline 22. All children born very preterm have similar sorts of problems at school & $43(70)$ & $47(77)$ & $7(-5,22)^{\mathrm{ns}}$ \\
\hline 24. Children born very preterm find it hard to sustain their attention in the & $18(30)$ & $55(90)$ & $61(49$ to 74$)$ \\
\hline
\end{tabular}
classroom

\begin{tabular}{|c|c|c|c|}
\hline $\begin{array}{l}\text { 25. Children born very preterm tend to be aggressive and get involved in } \\
\text { fights in the playground }\end{array}$ & $38(62)$ & $57(93)$ & 31 (19 to 45 ) \\
\hline $\begin{array}{l}\text { 26. Children born very preterm are more likely to have problems with eye- } \\
\text { hand coordination than their peers born at term }\end{array}$ & $16(26)$ & $61(100)$ & 74 (63 to 85 ) \\
\hline
\end{tabular}


Table 2 Continued

PB-KS items

Preresource Postresource \% diff postresource

n (\%) correct n (\%) correct preresource use $(95 \% \mathrm{Cl})$

28. Of all the subjects they study at school, children born very preterm 4 (7) $\quad 61$ (100) 93 (87 to 100)

are likely to have the greatest difficulties in mathematics

\begin{tabular}{|c|c|c|c|}
\hline $\begin{array}{l}\text { 29. Only a small proportion of children born very preterm need oxygen } \\
\text { during childhood to help them breathe }\end{array}$ & 24 (39) & $48(79)$ & 39 (27 to 55$)$ \\
\hline $\begin{array}{l}\text { 31. Of all the subjects they study at school, children born very preterm } \\
\text { are likely to have the greatest difficulties in reading }\end{array}$ & $16(26)$ & $60(98)$ & 72 (61 to 84$)$ \\
\hline $\begin{array}{l}\text { 32. Almost all children born very preterm who attend mainstream school } \\
\text { will have an education and healthcare plan }\end{array}$ & $43(70)$ & 54 (89) & 18 (7 to 32$)$ \\
\hline
\end{tabular}

$I Q$, intelligence quotient; ns, non-significant difference at $5 \%$.

and deficits in visuospatial processing (74\%) following preterm birth.

\section{Confidence in supporting children born preterm}

Participants' confidence in supporting the learning of children born preterm also increased significantly after accessing the e-learning resource (figure 1). Overall, 54 (89\%) participants felt adequately equipped to support the learning of children born preterm after using the resource compared with just $8(13 \%)$ before (\% difference $(95 \% \mathrm{CI}): 75$ (67 to 87$) ; \mathrm{p}<0.0001$ ), and $93 \%$ felt confident in supporting preterm-born children after using the resource compared with $23 \%$ before (70 (60 to 83); $\mathrm{p}<0.0001)$. After using the resource, $42(69 \%)$ felt they had received sufficient training about preterm birth compared with none prior to using the resource (69 (69 to 80$)$ ), and 50 (82\%) reported that they would consider prematurity when encountering a child who struggles at school compared with $14(23 \%)$ prior to using the resource (59 (48 to 73); $\mathrm{p}<0.0001$ ).

\section{Utility of the e-learning resource}

The resource was evaluated positively by participants (figure 2). Between $92 \%$ and $100 \%$ of participants felt

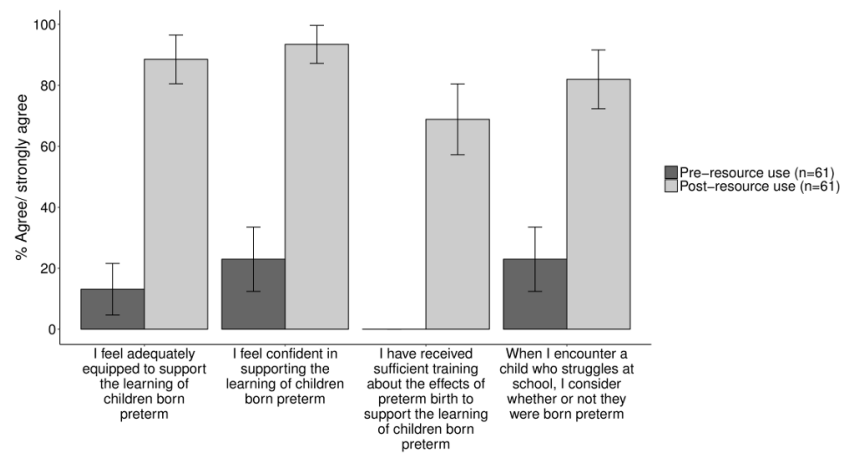

Figure 1 Proportion of participants who agreed with statements about confidence in supporting the learning of children born preterm before and after using the e-learning resource $(n=61)$. Error bars represent $95 \%$ Cls. that the resource was interesting, enjoyable, easy to use and pitched at the right level, the learning objectives were clear, and the multimedia elements added to their learning over written information. Additionally, participants felt the commentaries and case studies were engaging $(80 \%)$ and that the quizzes were valuable in showing what they had learnt $(88 \%)$. Overall, $97 \%$ reported that they would recommend the resource to others.

\section{DISCUSSION}

This interactive e-learning resource significantly improved education professionals' knowledge of the impact of preterm birth on children's development and learning and their confidence in supporting preterm-born children in the classroom. After using the resource there was a 2.6 SD increase in the mean PB-KS score, a difference that would be considered highly clinically significant. Using the PB-KS, the results of a previous national survey showed that education professionals' areas of poorest knowledge related to the most frequent adverse outcomes after preterm birth, namely mathematics difficulties, social difficulties and inattention, suggesting that preterm-born children may not be receiving appropriate support in the areas they need it the most. ${ }^{14}$ Importantly, we found that the greatest improvement in knowledge was in these areas, resulting in improved understanding of the risk for mathematics difficulties, poor social skills and inattention among children born preterm. This is particularly important since preterm children are part of a growing generation of children at risk for complex learning difficulties who present with profiles of learning need not previously experienced by schools. ${ }^{21}$ In particular, the special constellation of difficulties associated with preterm birth means that their problems may not be as readily detected in the classroom in the same way as in previous generations of children with SEN ${ }^{22}{ }^{23}$ As routine neonatal follow-up in the UK is recommended only to 2 years of age for children born $<30$ weeks' gestation (or 


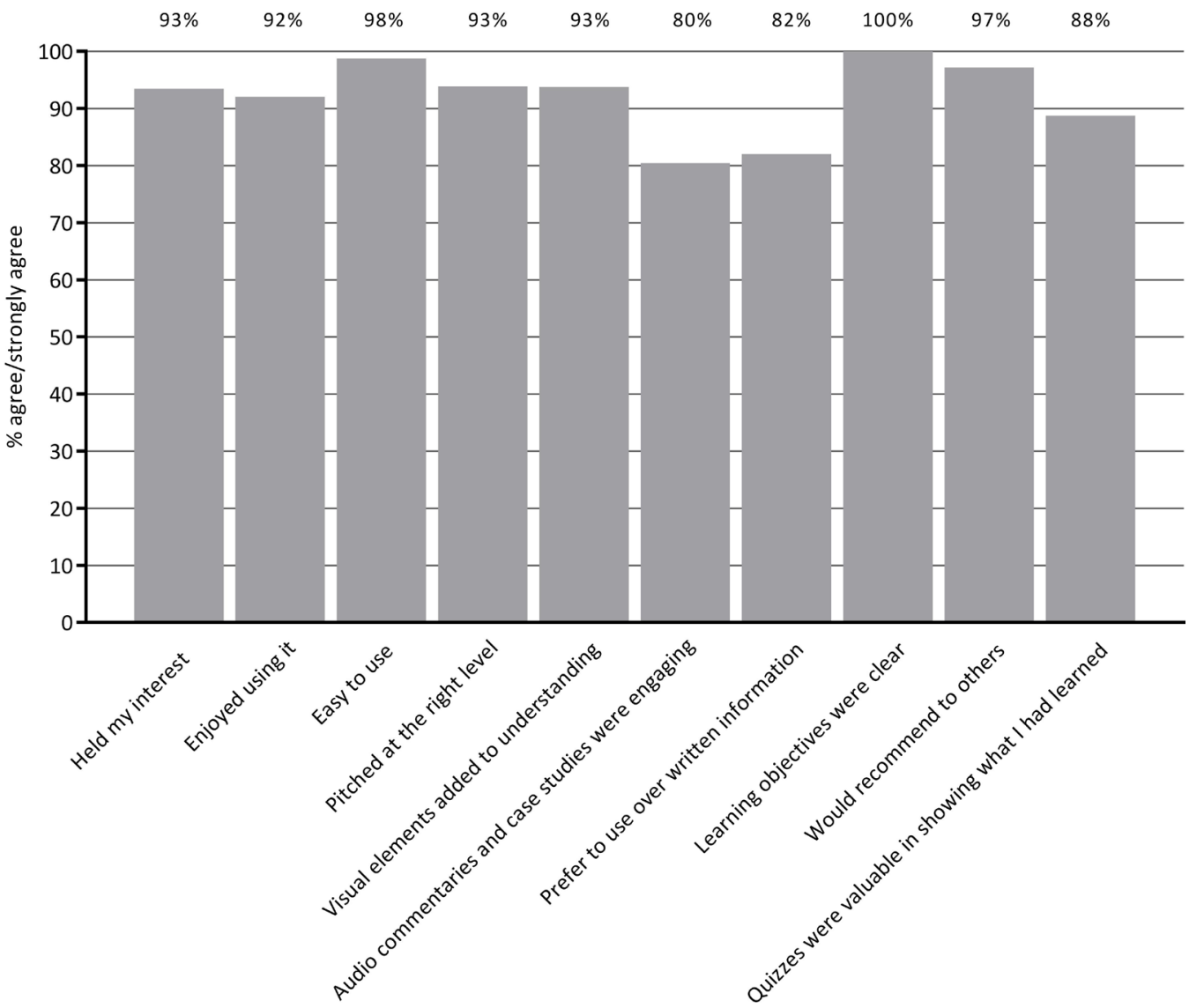

32-36 weeks' gestation with additional risk factors), or to 4 years for babies born $<28$ weeks, ${ }^{24}$ it is increasingly the role of teachers to identify those with difficulties and initiate support. Training for education professionals, such as provided by this e-learning resource, is therefore paramount.

Not only did the e-learning resource improve education professionals' knowledge and confidence, but its utility was rated extremely positively with $97 \%$ of participants agreeing that they would recommended it to others. Research relating to attention deficit/hyperactivity disorder and educational interventions has shown that identifying children with difficulties in the absence of providing teachers with strategies to support those children may lead to poor behavioural and academic outcomes due to potentially negative effects of labelling. ${ }^{25}$ Therefore, crucially, the e-learning resource was designed to include practical strategies that can be used to support the learning of children with the cognitive, mathematics and social-emotional difficulties most commonly associated with preterm birth.

Enhancing the knowledge of education professionals in supporting preterm-born children is of growing significance internationally. The continued increase in preterm birth rates coupled with the ongoing improvement in survival rates for extremely preterm babies ${ }^{26}$ means that there are increasing numbers of preterm survivors entering societies year on year. This results in greater demands being placed on education systems and their professionals to identify difficulties and provide support for these children in the long term. Even those children without severe disabilities or those born just a few weeks early may go on to have cognitive or social-emotional difficulties that may impact on their learning. ${ }^{2728}$ Despite marked improvements in neonatal care, there is, as yet, no robust evidence that this has translated into improved long-term outcomes, with some authors reporting increasing deficits in academic attainment and executive function over time for children born extremely preterm. $^{29} 30$

Recent national and European guidelines relating to developmental follow-up of preterm infants have recommended greater collaboration and information sharing between health and education services ${ }^{24}$ and improved training for education professionals about the specific constellation of problems experienced by children born preterm. ${ }^{31}$ Providing evidence-based information to teachers about health or behavioural conditions is considered to be important for appropriate educational management ${ }^{1112}$ and such interventions provide a potential approach to optimising outcomes for at-risk children with beneficial effects on a population level. ${ }^{32}$ Given that education professionals currently have limited knowledge in this area and feel ill-equipped to support preterm-born children, ${ }^{14}$ routine use of this resource by teachers and other education professionals may represent a key step 
forward in improving outcomes for these children. The e-learning resource has therefore been made available non-commercially to facilitate its use worldwide.

The study may be limited by the recruitment of a sample over-represented in terms of teachers with an existing interest in, and thus potentially greater knowledge of, preterm birth. Indeed, $85 \%$ of participants had previously received information about preterm birth compared with just $16 \%$ in a UK national survey. However, despite this, the mean PB-KS score pre-resource use in the present study was 13 (SD 6.2) compared with 15 (SD 5.5) in the national survey, ${ }^{14}$ suggesting that the present sample was representative of education professionals in terms of knowledge of preterm birth. In addition, $90 \%$ of our sample were female which is similar to the proportion of female teachers in state-funded primary schools in England (86\%). ${ }^{33}$ Moreover, we had sufficient power to detect a difference of $>3$ PB-KS scores, compared with the large 16-point difference observed, and we used a robust repeated measures design, although we did not include a control group who completed outcome assessments but did not use the resource or used an active control. Although knowledge and confidence improved through using the resource, $11 \%$ of participants did not feel adequately equipped and $7 \%$ not confident in supporting preterm children after using it. It is noteworthy that the resource was only used for a one-off period of up to 30 days for this study. In practice, professionals may use this over a longer period of time, dipping in and out of it as required, and in response to need (eg, identification of a preterm-born child) thus further developing competence and impacting on practice. It is also possible that a process of supported implementation may be beneficial when used in practice. We also note that of the 120 teachers who consented to participate, 61 completed the full study. It is possible that the method used to allow secure data collection and access to the resource may have been too cumbersome or time-consuming and may have discouraged completion of the study. This process was only implemented for this study and is not required to access the resource which is freely available for use online. Although this study included only primary school teachers, in future research we plan to evaluate the utility of the resource in different groups of education professionals, including secondary school teachers and educational psychologists. Finally, we do not know from this study whether improved knowledge and confidence translated into changes in practice in the classroom or in improved outcomes for children born preterm. These questions will be the focus of future investigations.

\section{Author affiliations}

${ }^{1}$ Health Sciences, University of Leicester, Leicester, UK

${ }^{2}$ Psychology, University of Nottingham, Nottingham, Notts, UK

${ }^{3}$ Centre for Mathematics Education, University of Loughborough, Loughborough, Leics, UK

${ }^{4}$ School of Education, University of Leicester, Leicester, UK

${ }^{5}$ Institute for Womens Health, University College London, London, UK

${ }^{6}$ School of Psychology, University of Ulster, Coleraine, Londonderry, UK
${ }^{7}$ Health Sciences, University of Nottingham, Nottingham, Notts, UK

Acknowledgements We would like to thank learning technologists Mike Taylor, Aaron Fecowycz, Lydia Jones and Cherry Poussa of the Health e-Learning and Media team at the University of Nottingham for their contribution to the development of the e-learning resource and assistance in the study. We are also indebted to the schools and the teachers who participated in the study and to all those who attended the stakeholder workshop for their contribution to the co-design of the e-learning resource.

Contributors SJJ was the principal investigator, contributed to study design, data collection and management, drafted the first version of the manuscript, revised it for important intellectual content and approved the final version for submission. DB contributed to study design and data collection, revised the manuscript for important intellectual content and approved the final version for submission. VB analysed the study data, revised the manuscript for important intellectual content and approved the final version for submission. SC, LC, CG, RG, NM, VS and HJW contributed to study design, revised the manuscript for important intellectual content and approved the final version for submission.

Funding This study was funded by a project grant from Action Medical Research (Grant Ref: GN2311). CG is funded by a Royal Society Dorothy Hodgkin Fellowship.

Competing interests None declared.

Patient consent for publication Not required.

Ethics approval The study was approved by the University of Leicester Research Ethics Committee (Ref: 16607).

Provenance and peer review Not commissioned; externally peer reviewed.

Data sharing statement Requests for access to deidentified study data relating to primary outcome measures should be emailed to the corresponding author using the information provided above. Please note, four participants did not provide consent for data sharing. As such only a reduced set of data for 57 participants can be made available. Study results in this subgroup are commensurate with the results from the total sample.

Open access This is an open access article distributed in accordance with the Creative Commons Attribution Non Commercial (CC BY-NC 4.0) license, which permits others to distribute, remix, adapt, build upon this work non-commercially, and license their derivative works on different terms, provided the original work is properly cited, appropriate credit is given, any changes made indicated, and the use is non-commercial. See: http://creativecommons.org/licenses/by-nc/4.0/.

\section{REFERENCES}

1. Brydges CR, Landes JK, Reid CL, et al. Cognitive outcomes in children and adolescents born very preterm: a meta-analysis. Dev Med Child Neurol 2018;60:452-68.

2. Allotey J, Zamora J, Cheong-See F, et al. Cognitive, motor, behavioural and academic performances of children born preterm: a meta-analysis and systematic review involving 64061 children. BJOG 2018;125:16-25.

3. Johnson S, Marlow N. Preterm birth and childhood psychiatric disorders. Pediatr Res 2011;69:11R-18.

4. MacKay DF, Smith GC, Dobbie R, et al. Gestational age at delivery and special educational need: retrospective cohort study of 407,503 schoolchildren. PLoS Med 2010;7:e1000289.

5. Quigley MA, Poulsen G, Boyle E, et al. Early term and late preterm birth are associated with poorer school performance at age 5 years: a cohort study. Arch Dis Child Fetal Neonatal Ed 2012;97:F167-F173.

6. Twilhaar ES, de Kieviet JF, Aarnoudse-Moens CS, et al. Academic performance of children born preterm: a meta-analysis and metaregression. Arch Dis Child Fetal Neonatal Ed 2018;103.

7. Mathiasen R, Hansen BM, Andersen AM, et al. Gestational age and basic school achievements: a national follow-up study in Denmark. Pediatrics 2010;126:e1553-e1561.

8. Bilgin A, Mendonca M, Wolke D. Preterm Birth/Low Birth Weight and Markers Reflective of Wealth in Adulthood: A Meta-analysis. Pediatrics 2018;142:142.

9. Basten M, Jaekel J, Johnson S, et al. and Adult Wealth: Mathematics Skills Count. Psychol Sci 2015;26:1608-19.

10. Chan E, Quigley MA. School performance at age 7 years in late preterm and early term birth: a cohort study. Arch Dis Child Fetal Neonatal Ed 2014;99:F451-F457.

11. Johnson MP, Lubker BB, Fowler MG. Teacher needs assessment for the educational management of children with chronic illnesses. J Sch Health 1988;58:232-5. 
12. Brook U, Galili A. Knowledge and attitudes of high school teachers towards pupils suffering from chronic diseases. Patient Educ Couns 2001;43:37-42.

13. Florian L, Black-Hawkins K. Exploring inclusive pedagogy. Br Educ Res J 2011;37:813-28.

14. Johnson S, Gilmore C, Gallimore I, et al. The long-term consequences of preterm birth: what do teachers know? Dev Med Child Neurol 2015;57:571-7.

15. Windle RJ, McCormick D, Dandrea J, et al. The characteristics of reusable learning objects that enhance learning: A case-study in health-science education. British Journal of Educational Technology 2011;42:811-23.

16. Wharrad $\mathrm{H}$, Windle $\mathrm{R}$. et a/Case studies of creating reusable inter professional e-learning objects. In: Bromage A, Clouder L, Gordon F, Thistlethwaite J, . eds. Interprofessional E-Learning and Collaborative Work: Practices and Technologies IGI Global, 2010.

17. Lymn JS, Bath-Hextall F, Wharrad HJ. Pharmacology education for nurse prescribing students - a lesson in reusable learning objects. BMC Nurs 2008;7:2.

18. Bath-Hextall $\mathrm{F}$, Wharrad $\mathrm{H}$, Leonardi-Bee J. Teaching tools in evidence based practice: evaluation of reusable learning objects (RLOs) for learning about meta-analysis. BMC Med Educ 2011;11:18.

19. Wharrad HJ, Sanderson-Mann J, McCandless F, et al. Using reusable learning objects to raise awareness and disseminate research findings about the impact of dyslexia in placement based learning. Disability in health and social care 2012;9:141-9.

20. Henderson D, Beer C, Wolke D, et al. Development and validation of a scale to assess knowledge of outcomes following preterm birth. Archives of Disease in Childhood 2012;97(Suppl 2):A353.

21. Special Schools and Academies Trust. Complex Learning Difficulties and Disabilities Research Project: The Specialist Schools and Academies Trust. 2014 http://complexld.ssatrust.org.uk/projectinformation.html (cited 19 Aug 2014).

22. Specialist School and Academies Trust. The Complex Learning Difficulties and Disabilities Research Project. Developing pathways to personalised learning. Final Report 2011.
23. Brogan E, Cragg L, Gilmore C, et al. Inattention in very preterm children: implications for screening and detection. Arch Dis Child 2014;99:834-9.

24. National Institue for Health and Care Excellence. Developmental follow-up of children and young people born preterm. Full Guideline. NG72. 2017.

25. Sayal K, Owen V, White K, et al. Impact of early school-based screening and intervention programs for ADHD on children's outcomes and access to services: follow-up of a school-based trial at age 10 years. Arch Pediatr Adolesc Med 2010;164:462-9.

26. Santhakumaran S, Statnikov Y, Gray D, et al. Survival of very preterm infants admitted to neonatal care in England 2008-2014 time trends and regional variation. Arch Dis Child Fetal Neonatal Ed 2018;103.

27. Hutchinson EA, De Luca CR, Doyle LW, et al. Victorian Infant Collaborative Study G. School-age outcomes of extremely preterm or extremely low birth weight children. Pediatrics 2013;131:e1053-61.

28. Johnson S, Strauss V, Gilmore C, et al. Learning disabilities among extremely preterm children without neurosensory impairment: Comorbidity, neuropsychological profiles and scholastic outcomes. Early Hum Dev 2016;103:69-75

29. Burnett AC, Anderson PJ, Lee KJ, et al. Trends in Executive Functioning in Extremely Preterm Children Across 3 Birth Eras. Pediatrics 2018;141:e20171958.

30. Spittle AJ, Cameron K, Doyle LW, et al. Victorian Infant Collaborative Study G. Motor Impairment Trends in Extremely Preterm Children: 1991-2005. Pediatrics 2018:141.

31. Jaekel J, Johnson S. European Standards of Care for Newborn Health: Meeting special needs at school, 2018.

32. Sayal K, Merrell C, Tymms P, et al. Academic Outcomes Following a School-Based RCT for ADHD: 6-Year Follow-Up. J Atten Disord 2015:108705471456258.

33. Department for Education. School Workforce in England: November 2017, 2018. 